\title{
ASSESSMENT OF CAPACITY BUILDING NEEDS AMONG MOTOR VEHICLE MECHANICS TRAINERS FOR THE USE OF AUTO SCAN TOOLS
}

\author{
A. O. Ezeama ${ }^{1, *}$, P. I. Obe ${ }^{2}$ and E. O. Ede ${ }^{3}$

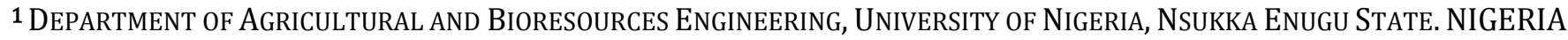 \\ 2,3DEPARTMENT OF INDUSTRIAL TECHNICAL EDUCATION, UNIVERSITY OF NiGERIA, NSUKKA, ENUGU STATE. NIGERIA \\ E-mail addresses:10sita.ezeama@unn.edu.ng,2pauline.obe@unn.edu.ng,3edegiwus@yahoo.com
}

\begin{abstract}
The motor vehicle mechanics trainers' are affected by the developments in the modern automobile technology (MAT) that brought about the use of auto scan tools for diagnosis and repair of modern vehicles in Nigeria. This study examined the capacity building needs among motor vehicle mechanics trainers in the use of auto scan tools. Three research questions and three null hypotheses guided the study. The study was carried out in three institutions where motor vehicle mechanics trade is offered as automobile technology or automobile education, three centers where auto scan tools are used for vehicle repairs and two technical colleges in Enugu state that offer motor vehicle mechanics (MVM) trade. The population of the study consisted of eighty three (83) MVM trainers, teachers and instructors. The instrument which was structured on two types of response scale (perceived importance and expressed performance) to elicit information on the use of auto scan tool for diagnosing some vehicle systems faults. Data collected were analyzed using the mean and the improvement needed index (INI) to answer the research questions. Then $t$ - test statistic was used to test the null hypotheses at $0.05 \%$ level of significance. The study found out that MVM trainers need capacity building in the use of auto scan tools for vehicle systems diagnosis and repairs. The study recommended that workshop/seminars should be organized by centers like the National center for equipment maintenance and development, the National automotive council and so on to enable MVM trainers acquire the required skills to meet up with the training job facing them.
\end{abstract}

Key words: capacity building, trainers, motor vehicle mechanics, diagnosis, auto scan-tool.

\section{INTRODUCTION}

To enhance effective training service delivery in Nigeria, trainers who are abreast of the trends in the theory and practice of motor vehicle mechanics should imbibe continuous professional development as a capacity building exercise. Ogbuanya stated that the dynamism of every changing technology in different field of science and technology requires sound and adequate training of individual in technical education [7]. The Automobile Teacher Education (ATE) planners should promote a view of information and communication technology (ICT) as a tool for enriching the teaching and learning environment of ATE because of current global technological advancement [5]. The advancement of ICT begot modern automotive technology (MAT) as it affects motor vehicle mechanics (MVM).The use of multimedia technologies is seen as a means of qualitative learning by facilitating access to MAT resources and services in ATE. These services will be delivered by a trainer who can access resources and impart same. MAT is in the area of Autotronics that is a branch of Mechatronics. However, level of familiarity with MAT will naturally differ among trainers which necessitate the study. It will be good for trainers to adapt themselves to new roles and skills in order to cope with the impending changes. The essence of the evaluation of trainers MAT skill needs is because they are the primary agents of innovation therefore; MAT skills among MVM trainers and teachers should be seen as an invaluable prerequisite that would help facilitate MVM teaching and learning procedure in this modern age of information explosion [9]. The educational infrastructure in Nigeria has been a 
critical element in supplying a highly qualified workforce to the automotive industry. As technology improvements in the vehicles and the manufacturing process dictate that jobs and skills change, so too must the educational offerings change as MVM trainers are expected to bring about the change. Hence vehicles of the future will require ever more sophisticated technology, changing the skills demanded of auto designers, engineers and production workers [5, 12, 15,]. In automobile education, the application of autotronics systems simulation as teaching aids with computer programmable soft-wares, auto scan tools for diagnosis, servicing and maintenance, autoanalyzers, solid work design and can-bus hard wares are used for automobile learning and practice [4]. Effective MAT professional development incorporates MVM trainers own aspirations, skills, knowledge, and understanding into the learning context. Even though it seems a complex venture but need to be surmounted because the traditional methods were put in a modern method [4]. Thus, the gap between traditional automotive technology (TAT) and MAT can be easily closed through skill improvement and professional MVM teacher development.

The capacity building needs of MVM trainers has changed significantly from manual to MAT because of technological developments in the automotive industries. Though, the need to give emphasis on MVM trainers and learners capacity building and skills development respectively, especially for the less privilege, educated, poor and school drop-out has been neglected for some time now throughout the African region [2]. The capacity building needs of MVM teachers on MAT will basically handle areas of maintenance, services and repair of automotive systems using auto scan tools. The end result will be that MVM teachers will be industry-certified and current in their field or area of knowledge as it regards MAT.

The automotive council of Nigeria in its bold effort at capacity building in the repairs and maintenance of new generation vehicles had, in collaboration with other stakeholders carried out the following:

- developed and launching of a curriculum for teaching automotive mechatronics in the informal sector;

- held critique workshop on the curriculum of automotive mechatronics;

- concluded arrangement for the printing of the curriculum and subsequent launching;
- the acquisition of mechatronics diagnostic equipment and tools for training Nigerian auto technicians is on going at specialized centers for teaching of automotive mechatronics [5].

\subsection{Statement of the Problem}

Modern automobile technology (MAT) which is an output of ICT revolves round current technological advancements in motor vehicle mechanics (MVM). It is obvious that graduates of technical colleges will perform better if they are well trained in their trade areas. Most Nigerian youths are unemployed because they lack the necessary skills. Again, some MVM technicians and teachers need skill improvement in MAT $[4,14,15,18$,$] .$

Digital divide which refers to the widening imbalance of access to ICT's between communities and countries which created an imbalance for equitable access to quality education in an electronic age has been blamed for the denial of the potentials of ICT in creating enabling learning environment for the $21^{\text {st }}$ century. Fortunately and task fully, the schools are very important institutions for bridging the digital divide in society because they represent focal points where many children from different communities converge for learning purposes [6]. Scholars such as Servon [10] argued that the technology gap should not be defined narrowly as a problem of access, hence training and content, should be included as other dimensions of the digital divide so that policy makers while making policies and programs to narrow the digital divide would not lose their focus [10]. It is therefore of paramount importance for teacher preparatory institutions to aim at developing in teachers ICT pedagogical competencies that will ensure that these teachers help the country to cross over to the positive side of the digital divide and keep pace on the information superhighway [3].

Facilities and resources such as computers, internet, auto scan tools, simulator and demonstrators are very important tools in the hands of teachers if MVM learning is to be embraced in earnest [4]. But the question is, are the facilities at the disposal of the MVM teachers in Nigeria? If they are, are they of international standard and are the teachers utilizing the resources? Do the automobile teachers have the requisite MAT skills to impact on the students' adequately? The supply and demand of competent and skilled MVM teachers is one of the critical problems in the teaching of automobile in technical colleges. And this called for the review of the skill improvement 
needs of the MVM teachers. Among MVM trainers in centers where auto scan tools are used and teachers in technical colleges' and institutions that offer MVM subjects, emphases should be made on how best to acquire MAT skills needed for MVM teaching and learning in Nigeria.

\subsection{Purpose of the Study}

The general objective of the study is to assess the capacity building needs among motor vehicle mechanics trainers in the use of auto scan tools. Specifically, the study will assess the skill improvement needs of motor vehicle mechanics teachers in the use of:

(1) launch code reader creader professional 123 scan tool for diagnosing engine faults;

(2) second-generation on board diagnostic (OBD2) scan tool for vehicles emission control systems;

(3) bi-directional auto scan tool for diagnosing vehicle brake system faults;

\section{METHODOLOGY}

\subsection{Research Questions}

The following research questions formed the basis for this research:

(1) What is the capacity building need of motor vehicle mechanics trainers in the use of a Launch code reader creader professional 123 scan tool in diagnosing engine faults?

(2) What is the capacity building need of motor vehicle mechanics trainers in the use of the second-generation on board diagnostic (OBD2) scan tool for diagnosing vehicles emission control systems?

(3) What is the capacity building need of motor vehicle mechanics trainers in the use of a bidirectional auto scan tool for diagnosing vehicle brake system faults?

\subsection{Hypotheses}

Three null hypotheses were proposed to be tested.

$\mathrm{Ho}_{1}$ : There is no significant difference between the mean scores of experienced and inexperienced motor vehicle mechanics (MVM) trainers on the skill improvement needs for the use of a Bidirectional auto scan tool for diagnosing vehicle brake system faults.

$\mathrm{Ho}_{2}$ : There is no significant difference between the mean scores of experienced and inexperienced motor vehicle mechanics (MVM) trainers on the skill improvement needs for the use of a Launch code reader creader professional 123 scan tool for diagnosing engine faults.

$\mathrm{Ho}_{3}$ : There is no significant difference between the mean scores of experienced and inexperienced motor vehicle mechanics (MVM) trainers on the skill improvement needs for the use of Secondgeneration on board diagnostic (OBD2) scan tool for vehicles emission control systems.

\subsection{Research Method}

The data collected were analyzed using mean and Improvement Needed Index (INI) to answer the research questions. Again, statistical t-test was used to test the hypotheses formulated. capacity building Need (CBN) was determined as follows: the mean (XI) of the important (that is the needed) category was determined for each item; the mean (XP) of the performance category was determined for each item; the performance gap (PG) was determined by finding the difference between the two means (that is subtracting $\mathrm{XP}$ from $\mathrm{XI}$ to get $\mathrm{PG}$ ).If $\mathrm{PG}$ is zero, it means that skill improvement is not needed for that item because the level at which the teachers perform the skill is equal to the level at which the skill is needed. If $P G$ is negative (-), it means skill improvement is not needed for that item because the level at which the teachers perform the skill is higher than the level at which it is needed. If PG is positive $(+)$, it means skill improvement is needed because the level at which the teachers perform the skill is lower than the level at which it is needed [8]. Also, the analysis was based on the instrument scoring weight/points. In taking decision for importance, any item with mean of 3.50 and above was considered as highly important, 2.50 - 3.49 was moderately important while any item with mean of less than 1.50 was considered as not important. In taking decision for performance, any item with mean of 3.50 and above was considered as high performance, 2.50 3.49 was moderate performance while any item with mean of less than 1.50 was considered as very low performance. The null hypotheses were tested at 0.05 level of significance. The decision for the null hypotheses is that if $\mathrm{t}$ - calculated value is less than $\mathrm{t}$ critical (table) value, accept the null hypotheses but if the $\mathrm{t}$ - calculated is more than $\mathrm{t}$-critical reject the null hypotheses.

\section{RESULTS AND DISCUSSION}

The data presented in table 1 showed that 5 out of 12 items had performance gap of 0.21 to 0.80 and were 
positive indicating that the trainers need capacity building in five items only. Seven out of 12 items in the section or cluster have negative and zero performance gap indicating that trainers capacity building is not needed on those items. Generally, the trainers need skill improvement in all the items having the cluster average XI and XP as 3.91 and 4.20 respectively but less emphasizes on the 7 items with negative and zero performance gap values.

Table 1: Mean Ratings of Motor Vehicle Mechanics Trainers' Capacity Building Needs in the Use of a Launch Code Reader Creader Professional 123 Scan Tool in Diagnosing Engine Faults

\begin{tabular}{|c|c|c|c|c|c|c|c|}
\hline $\mathrm{S} / \mathrm{N}$ & ITEMS & $\bar{X} I$ & SDI & PG & $\bar{X} P$ & SDP & REMARKS \\
\hline 1 & $\begin{array}{l}\text { Locate the Launch code reader creader professional } \\
123 \text { auto scan tool access point }\end{array}$ & 4.00 & 1.00 & 0.80 & 3.20 & 1.66 & CBN \\
\hline 2 & $\begin{array}{l}\text { Connect the Launch code reader creader professional } \\
123 \text { auto scan tool using the appropriate connector for } \\
\text { the vehicle }\end{array}$ & 4.13 & 1.09 & 0.21 & 3.92 & 1.28 & CBN \\
\hline 3 & Turn on the vehicle ignition & 4.61 & 0.70 & 0.65 & 3.96 & 1.54 & CBN \\
\hline 4 & $\begin{array}{l}\text { Turn on the Launch code reader creader professional } \\
123 \text { auto scan tool }\end{array}$ & 4.32 & 0.76 & 1.57 & 2.75 & 1.34 & CBN \\
\hline 5 & $\begin{array}{l}\text { Run the Launch code reader creader professional } 123 \\
\text { auto scan tool diagnostic program }\end{array}$ & 2.75 & 1.35 & -2.25 & 5.00 & 0.50 & CBNN \\
\hline 6 & $\begin{array}{l}\text { Navigate through vehicle engine system to access the } \\
\text { diagnostic trouble codes from the vehicle electronic } \\
\text { control module. }\end{array}$ & 3.93 & 1.54 & -0.82 & 4.75 & 0.55 & CBNN \\
\hline 7 & Record your findings for the engine system & 4.23 & 1.09 & 0.70 & 3.53 & 1.26 & CBN \\
\hline 8 & $\begin{array}{l}\text { Check what the engine system code mean and see if the } \\
\text { try fault indicated by the trouble codes need to be } \\
\text { corrected before you clear the codes. }\end{array}$ & 4.03 & 0.95 & -0.72 & 4.75 & 0.55 & CBNN \\
\hline 9 & $\begin{array}{l}\text { Carryout the repair of the engine system (Adjust spark } \\
\text { plugs to current specification, complete engine turn- } \\
\text { up, overhaul the fuel pump, set ignition timing and } \\
\text { clean \& set contact breaker point in distributor) }\end{array}$ & 3.66 & 0.90 & -1.34 & 5.00 & 0.50 & CBNN \\
\hline 10 & $\begin{array}{l}\text { Select the delete code option on the Launch code } \\
\text { reader creader professional } 123 \text { auto scan tool to clear } \\
\text { fault code. }\end{array}$ & 4.02 & 0.96 & -0.98 & 5.00 & 0.50 & CBNN \\
\hline 11 & $\begin{array}{l}\text { Repeat items 3-6 to recheck and reactivate the fault } \\
\text { code. }\end{array}$ & 3.32 & 1.48 & -1.68 & 5.00 & 0.50 & CBNN \\
\hline 12 & $\begin{array}{l}\text { Turn off the Launch code reader creader professional } \\
123 \text { auto scan tool and disconnect from the access } \\
\text { point. }\end{array}$ & 3.98 & 1.25 & -0.20 & 4.18 & 0.50 & CBNN \\
\hline & Section (cluster) average mean, PG and SD & 3.91 & 1.08 & 0.33 & 4.20 & 0.93 & \\
\hline
\end{tabular}

Keys: XI is the mean of important (needed) category, XP is the mean of performance category, PG is the performance gap, CBN is the capacity building needed, CBNN is the capacity building not needed, SDI is the standard deviation of important category, and SDP is the standard deviation of performance category. 
The data presented in table 2 showed that 8 out of 12 items had performance gap of 1.14 to 3.64 and were positive indicating that the trainers need capacity building in eight items only. Four out of 12 items in the section or cluster have negative and zero performance gap indicating that trainers' capacity building is not needed on those items. Generally, the trainers need skill improvement in all the items having the cluster average XI and XP as 4.31 and 2.71 respectively but less emphasizes on the 4 items with negative and zero performance gap values

Table 2: Mean Ratings of Motor Vehicle Mechanics Trainers Capacity Building Needs in the Use of The SecondGeneration on Board Diagnostic (Obd2) Scan Tool For Diagnosing Vehicles Emission Control Systems

\begin{tabular}{|c|c|c|c|c|c|c|c|}
\hline $\mathrm{S} / \mathrm{N}$ & ITEMS & $\bar{X} I$ & SDI & PG & $\bar{X} P$ & SDP & REMARKS \\
\hline 13 & $\begin{array}{l}\text { Locate the second-generation on board diagnostic } \\
\text { (OBD2)auto scan tool access point }\end{array}$ & 4.32 & 0.73 & 1.41 & 2.91 & 0.15 & CBN \\
\hline 14 & $\begin{array}{l}\text { Connect the second-generation on board } \\
\text { diagnostic (OBD2)auto scan tool using the } \\
\text { appropriate connector for the vehicle }\end{array}$ & 3.45 & 1.28 & 2.38 & 1.07 & 0.31 & CBN \\
\hline 15 & Turn on the vehicle ignition & 4.26 & 0.98 & 2.88 & 1.38 & 0.62 & CBN \\
\hline 16 & $\begin{array}{l}\text { Turn on the second-generation on board } \\
\text { diagnostic (OBD2)auto scan tool }\end{array}$ & 4.18 & 1.07 & -0.78 & 4.96 & 0.14 & CBNN \\
\hline 17 & $\begin{array}{l}\text { Run the second-generation on board diagnostic } \\
\text { (OBD2)auto scan tool diagnostic program }\end{array}$ & 4.71 & 0.76 & 3.64 & 1.07 & 0.31 & CBN \\
\hline 18 & $\begin{array}{l}\text { Navigate through vehicle emission control system } \\
\text { to access the diagnostic trouble codes from the } \\
\text { vehicle electronic control module. }\end{array}$ & 4.53 & 0.70 & 3.46 & 1.07 & 0.31 & CBN \\
\hline 19 & $\begin{array}{l}\text { Record your findings for the emission control } \\
\text { system }\end{array}$ & 4.48 & 0.51 & -0.48 & 4.96 & 0.14 & CBNN \\
\hline 20 & $\begin{array}{l}\text { Check what the emission control system code } \\
\text { mean and see if the try fault indicated by the } \\
\text { trouble codes need to be corrected before you } \\
\text { clear the codes. }\end{array}$ & 5.00 & 0.50 & 2.09 & 2.91 & 0.15 & CBN \\
\hline 21 & $\begin{array}{l}\text { Diagnose and carryout the repair of the emission } \\
\text { control system (full compression ratio repair and } \\
\text { mixture combustion control) }\end{array}$ & 4.22 & 1.08 & 3.13 & 1.09 & 0.30 & $\mathrm{CBN}$ \\
\hline 22 & $\begin{array}{l}\text { Select the delete code option on the second- } \\
\text { generation on board diagnostic (OBD2) auto scan } \\
\text { tool to clear fault code. }\end{array}$ & 4.50 & 0.05 & -0.40 & 4.90 & 0.30 & CBNN \\
\hline 23 & $\begin{array}{l}\text { Repeat items 3-6 to recheck and reactivate the } \\
\text { fault code. }\end{array}$ & 3.95 & 1.55 & 2.61 & 1.34 & 0.65 & $\mathrm{CBN}$ \\
\hline 24 & $\begin{array}{l}\text { Turn off the second-generation on board } \\
\text { diagnostic (OBD2) auto scan tool and disconnect } \\
\text { from the access point. }\end{array}$ & 4.13 & 1.22 & -0.83 & 4.96 & 0.14 & CBNN \\
\hline & Section (cluster)average mean, $\mathrm{PG}$ and SD & 4.31 & 0.90 & 1.59 & 2.71 & 0.29 & \\
\hline
\end{tabular}

Keys: XI is the mean of important (needed) category, XP is the mean of performance category, PG is the performance gap, CBN is the capacity building needed, CBNN is the capacity building not needed, SDI is the standard deviation of important category, and SDP is the standard deviation of performance category. 
The data presented in table 3 showed that 5 out of 12 items had performance gap of 0.03 to 3.26 and were positive indicating that the trainers need skill improvement in five items only. Seven out of 12 items in the section or cluster have negative and zero performance gap indicating that trainers skill improvement is not needed on those items. Generally, the trainers need skill improvement in all the items having the cluster average XI and XP as 3.80 and 3.74 respectively but less emphasizes on the 7 items with negative and zero performance gap values.

\subsection{Testing of Hypotheses}

\subsection{1 $\mathrm{Ho}_{1}$}

There is no significant difference between the mean scores of experienced and inexperienced motor vehicle mechanics (MVM) trainers on the capacity building needs for the use of a Launch code reader creader professional 123 scan tool for diagnosing engine faults.

The test suggested that the difference between the mean of experienced and the inexperienced MVM trainers in the use of a Launch code reader creader professional 123 scan tool for diagnosing engine faults is not statistically significant. Therefore, the null hypothesis is accepted. The $\mathrm{t}$ - calculated is less than $\mathrm{t}$ critical therefore there is no significant difference between the mean responses of experienced and the inexperienced MVM trainers in the use of a Launch code reader creader professional 123 scan tool for diagnosing engine faults.

Table 3: Mean Ratings of Motor Vehicle Mechanics Trainers Capacity Building Needs in the Use of A Bi-Directional Auto Scan Tool For Diagnosing Vehicle Brake System Faults.

$\mathrm{S} / \mathrm{N} \quad$ ITEMS

Locate the bi-directional auto scan tool access point

$\bar{X} I \quad$ SDI

PG

$\bar{X} P \quad$ SDP

REMARKS

Connect the bi-directional auto scan tool using the

appropriate connector for the vehicle

27 Turn on the vehicle ignition

Turn on the bi-directional auto scan tool

Run the bi-directional auto scan tool diagnostic program

Navigate through vehicle brake system to access the

diagnostic trouble codes from the vehicle electronic control module.

Record your findings for the brake system

Check what the brake system code mean and see if the try

fault indicated by the trouble codes need to be corrected

before you clear the code.

33 Perform the repair of the brake system

Select the delete code option on the bi-directional auto scan tool to clear fault code.

Repeat items 3-6 to recheck and reactivate the fault code.

Turn off the bi-directional auto scan tool and disconnect from the access point.

3.93

3.93

1.27

3.90

0.46

CBN

3.45

4.05

1.25

$-1.51$

4.96

0.14

CBNN

4.02

4.02

1.18

$-0.85$

$\begin{array}{ll}4.90 & 0.30\end{array}$

CBNN

$\begin{array}{llllll}4.33 & 0.81 & 3.26 & 1.07 & 0.31 & \text { CBN }\end{array}$

$\begin{array}{llllll}3.97 & 0.93 & 2.59 & 1.38 & 0.63 & \text { CBN }\end{array}$

1.08

$-1.30$

4.96

0.14

CBNN

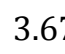

$\begin{array}{lllll}1.63 & 2.60 & 1.07 & 0.31 & \text { CBN }\end{array}$

4.03

1.07

$-0.74$

4.96

0.14

CBNN

$4.03 \quad 1.14$

$-0.93$

$\begin{array}{ll}4.96 & 0.14\end{array}$

CBNN

$2.41 \quad 1.62$

$-2.49$

$\begin{array}{ll}4.90 & 0.30\end{array}$

CBNN

$3.96 \quad 1.36$

$-1.00$

4.96

0.14

CBNN

Keys: XI is the mean of important (needed) category, XP is the mean of performance category, PG is the performance gap, CBN is the capacity building needed, CBNN is the capacity building not needed, SDI is the standard deviation of important category, and SDP is the standard deviation of performance category. 


\subsection{2 $\mathrm{Ho}_{2}$}

There is no significant difference between the mean scores of experienced and inexperienced motor vehicle mechanics (MVM) trainers on the capacity building needs for the use of Second-generation on board diagnostic (OBD2) scan tool for vehicles emission control systems.

The test suggested that the difference between the mean of experienced and the inexperienced MVM trainers in the use of Second-generation on board diagnostic (OBD2) scan tool for vehicles emission control systems faults is statistically significant. Therefore, the null hypothesis is rejected. The $\mathrm{t}$ calculated is not less than $t$ - critical therefore there is significant difference between the mean responses of experienced and the inexperienced MVM trainers in the use of Second-generation on board diagnostic (OBD2) scan tool for vehicles emission control systems.

\subsection{3 $\mathrm{Ho}_{3}$}

There is no significant difference between the mean scores of experienced and inexperienced motor vehicle mechanics (MVM) trainers on the capacity building needs for the use of a Bi-directional auto scan tool for diagnosing vehicle brake system faults. The test suggested that the difference between the mean of experienced and the inexperienced MVM trainers in the use of a Bi-directional auto scan tool for diagnosing vehicle brake system faults is not statistically significant. Therefore, the null hypothesis is accepted. The t- calculated is less than t- critical therefore there is no significant difference between the mean responses of experienced and the inexperienced MVM trainers in the use of a $\mathrm{Bi}$ directional auto scan tool for diagnosing vehicle brake system faults.

\section{RESULTS AND DISCUSSION}

The findings from tables 1 to 3 showed average clusters mean above 3.50 and indicating that respondents (experienced and inexperienced MVM trainers) agreed to a high level that there are capacity building needs of motor vehicle mechanics trainers in the use of the auto scan tools vehicle faults. Tables 4 and 6 showed no significant difference between the mean responses of experienced and inexperienced MVM trainers in the use of Bi-directional auto scan tool for diagnosing vehicle brake system faults; and in the use of a Launch code reader creader professional 123 scan tool for diagnosing engine faults. Tables 5 showed significant difference between the mean responses of experienced and inexperienced MVM teachers in the use of Second-generation on board diagnostic (OBD2) scan tool for vehicles emission control systems.

Table 4: T- Test of Difference Between the Mean Rating of Experienced and Inexperienced Motor Vehicle Mechanics (Mvm) Trainers on the Capacity Building Skill Improvement Needs For The Use of a Launch Code Reader reader Professional 123 Scan Tool For Diagnosing Engine Faults.

\begin{tabular}{cccccccc}
\hline Trainers & $\bar{X}$ & SD & N & DF & T-calculated & T-critical & Decision \\
\hline Experienced & 3.91 & 1.08 & 22 & 27 & 0.69 & \pm 2.05 & Accept \\
Inexperienced & 4.20 & 0.93 & 7 & & & & \\
\hline
\end{tabular}

Table 5: T- Test of Difference Between the Mean Rating of Experienced And Inexperienced Motor Vehicle Mechanics (Mvm) Trainers on the Capacity Building For the Use of Second-Generation on Board Diagnostic (Obd2) Scan Tool For Vehicles Emission Control Systems.

\begin{tabular}{cccccccc}
\hline Trainers & $\bar{X}$ & SD & N & DF & T-calculated & T-critical & Decision \\
\hline Experienced & 4.31 & 0.90 & 22 & 27 & 7.30 & \pm 2.05 & Reject \\
Inexperienced & 2.71 & 0.29 & 7 & & & & \\
\hline
\end{tabular}

Table 6: T-Test of Difference Between the Mean Rating of Experienced and Inexperienced Motor Vehicle Mechanics (Mvm) Trainers on the Capacity Building Needs For the Use of a Bi-Directional Auto Scan Tool for Diagnosing Vehicle Brake System Faults.

\begin{tabular}{llllllll}
\hline Trainers & $\bar{X}$ & SD & N & DF & T-calculated & T-critical & Decision \\
\hline Experienced & 3.80 & 1.18 & 22 & 27 & 0.26 & \pm 2.05 & Accept \\
Inexperienced & 3.74 & 0.26 & 7 & & & & \\
\hline
\end{tabular}


Also it was noted that performance efficiency of the auto scan tools were not regular as a result of chance factor, sample error, non familiarity of the teachers with auto scan tools involved and code customization of auto scan tools.

The finding agreed with Abah (2011) who outlined that, lecturers in tertiary institutions in North Western states of Nigeria possessed average competencies in practical's, workshop cum classroom management and theories of automobile technology [1]. The work recommended that seminars and workshops should be organized for lecturers of automobile technology on methods of teaching practical, effective classroom cum workshop management. The $\mathrm{t}$ - calculated is less than $\mathrm{t}$ - critical.

For MVM trainers not to be rendered valueless there is need for their skill improvement which did agree with Usman, (2007) study which revealed that the orthodox skills of auto technicians have been rendered valueless by emergence of computer technology in modern automobiles, and auto technicians lack knowledge and high technician skills needed to repair modern automobiles [11]. Thus, tcalculated were greater than t-critical showing significant differences.

Based on the data analyzed, the following were principal findings:

1. MVM trainers need capacity building in the use of Launch code reader creader professional 123 scan tool for diagnosing engine faults as it concern mainly:-

- Locate the auto scan tool access point

- Connect the auto scan tool using the appropriate connector for the vehicle

- Turn on the vehicle ignition

- Turn on the auto scan tool

- Record your findings for the engine system

2. MVM trainers need capacity building in the use of Second-generation on board diagnostic (OBD2) scan tool for vehicles emission control systems faults as it concern mainly:-

- Locate the auto scan tool access point

- Connect the auto scan tool using the appropriate connector for the vehicle

- Turn on the vehicle ignition

- Run the auto scan tool diagnostic program

- Navigate through vehicle emission control system to access the diagnostic trouble codes from the vehicle electronic control module.

- Check what the emission control system code mean and see if the try fault indicated by the

Nigerian Journal of Technology trouble codes need to be corrected before you clear the codes.

- Check what the emission control system code mean and see if the try fault indicated by the trouble codes need to be corrected before you clear the codes.

- Diagnose and repair the emission control system (full compression ratio repair and mixture combustion control).

\section{CONCLUSION}

Motor vehicle mechanics teachers have the need for capacity building in the use of the following auto scan tools: Launch code reader creader professional 123 scan tool for diagnosing engine faults; Secondgeneration on board diagnostic (OBD2) scan tool for vehicles emission control systems; Bi-directional auto scan tool for diagnosing vehicle brake system faults in the training, learning and of motor vehicle mechanics in the institutions and centers that use auto scan tools. This assertion is affirmed by the findings of the study which agreed on a general note that there is need for MVM teachers to improve in use of modern automobile technology facilities in training.

\section{RECOMMENDATIONS}

Based on the result of the study, the following recommendations were made:

1. Motor vehicle mechanics departments should be well equipped with modern automobile technology facilities and competent teachers employed to man the facilities in order to enhance teaching and learning of the trade in our colleges.

2. The findings of the study should be made available to policy makers like the automobile council of Nigeria, educational institutions and other cooperate bodies/agencies of education to enable tem effect necessary changes in the MVM programme with respect to its theories and practical's.

\section{REFERENCES}

[1] Abah, A.. Evaluation of the Competencies possessed by lecturers of Automobile technology in tertiary institution in North Western States of Nigeria. Unpublished M.Ed. Thesis, Department of Vocational Teacher Education, University of Nigeria Nsukka. 2011.

[2] Abubakar, H.; Yahaya, U. O. and Tijani, A..autotronics course - aninnovative approach in modern automotive technology education in Africa

Vol. 35, No. 4, October 2016. 
for sustainable development http://www.ijser.org Accessed on 14th of July, (2015).

[3] Akudolu, L. Quest for Teacher Needed Competencies for Instructional Use of ICT Paper presented at the 2006 National Conference of Nigerian Primary and Teacher Education Association-ESUT Agbani. (2006)

[4] Ezeama, A. O. Capacity building needs of motor vehicle mechanics teachers in technical colleges in Enugu state. Unpublished B.Sc.(education) project report, Department of Industrial Technical Education, University of Nigeria Nsukka. (2016).

[5] http://www.nac.org.ng/achievements.php, retrieved on $2^{\text {nd }}$ July 2015.

[6] Mutual, S. M. and Mutula, D. L.. "ICT Information in Botswana Secondary schools: Digital Divide Factor and Implications for Information Literacy". African Journal of Library Archives and Information Science Vol.17 (2) pp.126-128. (2007).

[7] Ogbuanya T C. The effect of multiple intelligencebased instructional approaches on student's cognitive achievement in Technical College. Electronics Technology 7(1): 1-13. (2010).

[8] Olaitan, S. O., Araribe, M. O. and Nwobu V. I. Capacity building needs of teachers of agriculture for effective teaching in upper basic schools in Abia state. Paper presented at the annual conference of Nigerian vocational association (NVA) on quality assurance in vocational technical education, University of Nigeria, Nsukka on the theme "Teacher preparation and vision 20:20:20 in Nigeria". (2009).
[9] Oyeronke A and Fagbohun, M An Assessment of Computer and ICT Skills Among Secondary School Teachers in Ota Ogun State. Library Philosophy and Practice (e-journal).http://digitalcommons.unl. edu/libphilprac. Assessed on November (2013).

[10] Servon, Lisa.. Bridging the digital divide: Technology, community, and public policy. Malden, MA: Blackwell, (2002)

[11] Usman. Human resources development needs of Automobile technicians for effective maintenance of Automobiles in Niger State unpublished MED Thesis University of Nigeria Nsukka. (2007).

[12] What does the computer in a car do?" 01 April. HowStuffWorks.com. (2000). <http://auto.howstuffworks.com/under-thehood/trends-innovations/question113.htm $>\quad 02$ July (2015).

[13] William Blair. "IC Die Photography". Retrieved 7-23. (2015).

[14] www.aaicar.com, making sense of engine sensors, retrieved on $2^{\text {nd }}$ July 2015

[15] www.cd $x$ ete $x$ book.com / safely info vehinfo / information / clear dtc., retrieved on $4^{\text {th }}$ July (2015).

[16] www.google.com.ng/search? = Procedures +for +using + scan +tools $+\&$ client $=$ ms opera mini, retrieved on $2^{\text {nd }}$ July (2015).

[17] www.popularmechanics.com.ng=procedures of using auto scan, retrieved on $23^{\text {rd }}$ July (2015).

[18] www.therangerstation.com/tech library/diagr ams/TFI igniti, retrieved on $4^{\text {th }}$ July, (2015.) 